\title{
Electing a Diverse Canada: The Representation of Immigrants, Minorities, and Women
}

\author{
Caroline Andrew, John Biles, Myer Siemiatycki and Erin \\ Tolley, UBC Press (2008) 278 pages, ISBN-13: 978-0774814850
}

\section{Linda Trimble}

Published online: 5 April 2011

(C) Springer Science+Business Media B.V. 2011

The urban centers with Canada's largest concentrations of immigrant and ethnoracially diverse populations have been systematically underrepresented in the House of Commons. Federal legislation introduced on April 1, 2010 will adjust the number of seats in the House of Commons to accommodate Canada's fastest-growing cities in British Columbia, Alberta, and Ontario. ${ }^{1}$ But will adding 30 new seats in these jurisdictions help make our federal government more 'like us'; that is, more reflective of the "dynamic, diverse urban nation that Canada has become and is still becoming" ? ${ }^{2}$ The evidence presented in Electing a Diverse Canada suggests the answer is no. Elected officials in key Canadian jurisdictions do not mirror the populations that elect them. As the authors demonstrate, even the most demographically diverse ridings are typically represented by the archetypal Canadian elected official- "male, White, middle-class, middle-aged, Christian, Canadian-born and majority-language speaking" (p. 18).

Framed by integrative introductory and concluding chapters, the volume includes nine case studies of elected representatives in 11 Canadian cities, chosen for their size, history of immigration and level of ethno-racial diversity. These nine chapters present a snapshot of the politicians elected to three levels of government-municipal, provincial and federal-in 2005. Surveys were supplemented by secondary analysis to measure a series of diversity characteristics: ethnicity, visible minority status, immigration status, Aboriginality, sex, religion, language, age, and education. A tenth chapter maps changes in the presence of ethno-racial minorities in the House of Commons between 1993 and 2004. The introduction situates the case studies within a systematic theoretical and methodological framework and the concluding chapter

\footnotetext{
${ }^{1}$ John Ibbitson, 2010. "Fastest-growing provinces to benefit from Tories' Commons overhaul." The Globe and Mail, 1 April.

${ }^{2}$ John Ibbitson, 2010. "Unequal votes threatening Canadian democracy, study finds." The Globe and Mail, 23 March.
}

L. Trimble $(\bowtie)$

Department of Political Science, University of Alberta, Edmonton, AB, Canada

e-mail: linda.trimble@ualberta.ca 
summarizes the data, presenting a cross-sectional analysis that is, as the editors note, unsettling (p. 257). The goal of seeing ourselves, in all our diversity, in our city councils, legislatures, and parliaments remains remote.

The strengths of the volume are many. As a benchmark study of diversity among elected officials at three levels of government in a well-chosen sample of Canadian cities, the book paints a clear portrait of Canada's politicians. The methodology is rigorous, methodically applied, and replicable. Although the city case study chapters follow a strict template, with common measures, concepts and research questions, they are neither repetitious nor tedious. Each has its own unique flavor and each engages the reader with intriguing historical facts as well as contemporary anecdotes and observations. For readers seeking a pithy summary, data on three core variables are effectively synthesized in the concluding chapter. A table highlights the proportionality, relative to each group's share of the population, of the sex, visible minority status, and immigrant status of representatives elected by the 11 cities analyzed in this volume, as well as in the House of Commons (pp. 259-60).

Some of the findings are unsurprising. As of 2005, women held less than half of the positions that would be theirs if fairly represented. Visible minorities were the most under-represented of the three groups, "overwhelmingly marginalized in the ranks of elected politicians" (p. 258). Other trends can only be revealed by the comparative analysis offered in this volume. For instance, there was much greater variability in the representation of visible minorities than of women or foreign-born Canadians. In five jurisdictions, visible minorities were more proportionally represented than were women; in three cities they were not represented at all, at any level of government. Some results are surprising. For instance, Calgary and Edmonton (not Vancouver or Toronto or Montreal) were "closest to reaching equitable representation of visible minorities relative to their share of the population" (p. 258). Foreign-born Canadians reflected the most equitable levels of representation and, in Regina and Edmonton, were statistically over-represented (p. 258). The electoral success of groups such as Punjabi Sikhs in the House of Commons, and Canadians of Filipino origin in Winnipeg, lead the editors to observe that there are some hopeful "emerging archetypes of greater diversity" (p. 18).

It is important to remember that the city-based data do not capture fluctuations within jurisdictions. As such, the editors" contention that the "inevitable, over-time" argument - the idea that progress is inevitable and parity is simply a matter of time- "is neither true nor useful" (p. 18) falls flat because the findings from the 11 cities do not actually measure change. Will Canada's cities follow the trends illustrated by the House of Commons between 1993 and 2004, of electing more foreign-born Canadians while continuing to under-represent women and visible minorities? Will women continue to face the hardest electoral glass ceiling, with their levels of representation stalled since 1997? While this volume has made a significant and long overdue conceptual and empirical contribution to our understanding of descriptive political representation, a follow-up volume dedicated to tracking the numbers over several election cycles will be most enthusiastically received.

Linda Trimble is a Professor in the Political Science Department at the University of Alberta in Edmonton, Canada. Her research explores media coverage of politics and women's legislative representation. She is the co-editor of Mediating Canadian Politics and Representing Women in Parliament: A Comparative Study. 